\title{
Antalya ili aksu ilçesinde patlıcan yetiştirilen sera topraklarının verimlilik durumlarının belirlenmesi
}

\author{
Determination of fertility status of eggplant grown greenhouse soils in the Antalya-Aksu district
}

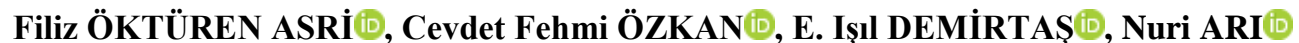

Batı Akdeniz Tarımsal Araştırma Enstitüsü Müdürlüğü, Antalya

Sorumlu yazar (Corresponding author): F. Öktüren Asri, e-posta (e-mail): filiz.okturenasri@tarimorman.gov.tr

Yazar(lar) e-posta (Author e-mail): cfozkan@gmail.com, eemrahoglu@mynet.com, arinuri@mynet.com

MAKALE BİLGİİ

Alınış tarihi 12 Mart 2019

Düzeltilme tarihi 19 Nisan 2019

Kabul tarihi 26 Nisan 2019

\section{Anahtar Kelimeler:}

Patlican

Toprak verimliliği

Makro besin elementleri
ÖZ

Antalya ili Aksu ilçesinde patlıcan yetiştirilen sera topraklarının verimlilik durumlarının belirlenmesi amacıyla yapılan çalıșmada, 36 farklı seradan $(0-30 \mathrm{~cm}$, toprak derinliğinden $)$ toprak örnekleri alınmıştır. Alınan toprak örneklerinde bünye, $\mathrm{pH}$, elektriksel iletkenlik (EC), kireç $\left(\mathrm{CaCO}_{3}\right)$, organik madde, toplam azot $(\mathrm{N})$, alınabilir fosfor $(\mathrm{P})$, değişebilir potasyum $(\mathrm{K})$, kalsiyum $(\mathrm{Ca})$ ve magnezyum $(\mathrm{Mg})$ analizleri yapılmıştır. Analiz sonuçlarına göre, sera toprak örneklerinin bünyeleri kumlu tın'dan killi tın'a, kadar değişkenlik göstermekte olup, kireçli, hafif alkalin ve alkalin karakterdedir. İncelenen örneklerin organik madde miktarlarının yetersiz, toplam azot ve değişebilir potasyum konsantrasyonlarının çok fakirden çok iyiye değişken, alınabilir fosfor konsantrasyonlarının yeterli, değişebilir kalsiyum ve magnezyum konsantrasyonlarının ise yüksek olduğu belirlenmiştir.

\section{ARTICLE INFO}

Received 12 March 2019

Received in revised form 19 April 2019

Accepted 26 April 2019

Keywords:

Eggplant

Soil fertility

Macro nutrient elements

\begin{abstract}
This study was carried out to determine some fertility properties of greenhouse soils in the Aksu district. For this aim, 36 soil samples were taken from Aksu. The analyses were made to determine $\mathrm{pH}$, electrical conductivity $(\mathrm{EC})$, lime $\left(\mathrm{CaCO}_{3}\right)$, texture, organic matter, total $\mathrm{N}$, available $\mathrm{P}$, exchangeable $\mathrm{K}, \mathrm{Ca}$ and $\mathrm{Mg}$ in soil samples. Results obtained showed that, soils of the greenhouses studied had a texture ranging from sandy loam to clay loam, slight alkaline and alkaline. Organic matter contents of soils were insufficient. Total N and exchangeable potassium concentrations ranged from poor to very high levels. Available $\mathrm{P}$ concentrations were sufficient, exchangeable $\mathrm{Ca}$ and $\mathrm{Mg}$ concentrations were high.
\end{abstract}

\section{Giriș}

İnsanlığın gıda ihtiyacını karşılamak üzere yetiştiriciliği yapılan en eski sebze türlerinden birisi olan patlıcan, Dünyada 1871382 ha üretim alanı ve 49.5 milyon tonluk üretim miktarıyla patates ve domatesten sonra üçüncü önemli sebzedir. Türkiye 850 bin ton patlıcan üretim miktarıyla beşinci en büyük (Çin, Hindistan, İran ve Misırdan sonra) üretici ülke konumundadır. 2015 yılında ortalama 20 bin ton patlıcan ihraç edilen ülkemizde, 12923470 dolar gelir sağlanmıştır (TÜİK 2015). Antalya 161 bin ton patlıcan üretim miktarıyla Türkiye üretiminin \%20'sini karşılamaktadır. Yetiştirilen patlıcanın \%30'u örtüaltında, \%70'i ise açık tarla koşullarındadır. Örtüaltı yetiştiriciliğinde üretim döneminin uzun olması, verimli hibrit çeşitlerin kullanılması yetiştiricilikte fazla miktarda gübrenin kullanılmasına neden olmaktadır. Ancak toprak pH'sı, kireç içeriği, organik madde miktarı ve bitki besin elementlerinin konsantrasyonu gibi faktörler dikkate alınmadan yapılan yoğun gübreleme beraberinde çevre sorunlarını getirmektedir.
Uygulamadaki durumun bilinmesi araştırıcıları yoğun yetiştiricilik yapılan alanların sorunlarını belirlemeye yöneltmiştir. Sönmez ve Kaplan (2007), Antalya ili Demre ilçesinde domates yetiştirilen sera topraklarının aşırı kireçli, alkali reaksiyonlu, çoğunlukla hafif ve orta tuzlu, düşük organik madde içeriğine sahip olduğunu bildirmişlerdir. Benzer şekilde Işıkhan ve Sönmez (2017), Elmalı yöresinde domates yetiştirilen sera topraklarının organik madde miktarlarının düşük, kireç içeriklerinin yüksek ve tuzluluk probleminin olmadığını belirtmişlerdir. Bugün ülkemizde sebze yetiştirilen seralarda fiziksel ve kimyasal özellikleri birbirinden çok farklı topraklar üzerinde yetiştiricilik yapmaktan kaynaklı bitki besleme sorunları yaygın olarak görülmektedir. Gübreleme uygulamalarının toprak analiz sonuçlarına dayandırılmadan bilinçsizce yapılması önemli sorundur. Bu çalışmada Antalya ili Aksu ilçesinde patlıcan yetiştirilen sera topraklarının verimlilik düzeyleri araştırılmıştır. 


\section{Materyal ve Yöntem}

Çalışmada, Antalya İli Aksu ilçesinde patlıcan yetiştiriciliği yapılan seralardan Batı Akdeniz Tarımsal Araştırma Enstitüsü Yaprak ve Toprak Analiz Laboratuvarı'na üreticiler tarafindan 2018 y1lında getirilen 36 adet toprak örneği materyal olarak kullanılmıştır.

Toprakların bünyesi Bouyoucos hidrometre (Bouyoucos 1955) metoduna göre, $\mathrm{pH}$ ve EC'si 1/2.5 toprak su karışımında (Jackson 1967), kireç içeriği scheibler kalsimetresi kullanılarak (Evliya 1964), organik madde miktarı modifiye Walkey-Black (Black 1965) metoduna göre belirlenmiştir. Toplam N modifiye Kjeldahl (Kacar 1995), alınabilir P Olsen (Olsen ve Sommers 1982), değişebilir K, Ca ve Mg analizleri $1 \mathrm{~N}$ Amonyum asetat (Kacar 1995) yöntemine göre yapılmıştır.

\section{Bulgular}

Antalya ili Aksu ilçesindeki patlıcan seralarından alınan toprak örneklerine ait fiziksel ve kimyasal analiz sonuçlarının minimum ve maksimum değerleri Çizelge 1'de, sınır değerlerine göre sınıflandırılması ise Çizelge 2'de verilmiştir. İncelenen sera topraklarının $\mathrm{pH}$ değerleri 6.9-8.7 arasında değişmekte olup (Çizelge 1); örneklerin \%16'sının nötr, $\% 37$ 'sinin hafif alkalin ve \%47'sinin alkalin karakterde olduğu saptanmıştır (Çizelge 2). Örnekleme yapılan sera topraklarının kireç içerikleri \%0.8-54.5 arasında değişmekte olup; Evliya (1964)'ya göre sınıflandırıldığında örneklerin \%6'sının düşük, \%8'inin kireçli, \%11'inin yüksek, \%36'sının çok yüksek ve \%39'unun aşırı kireçli olduğu tespit edilmiştir. İncelenen toprak örneklerinin \%75'inin kireç içeriğinin yüksek ve \%47'sinin alkalin karakterde olmasından kaynaklı beslenme sorunlarıyla karşılaşılmaması için, uygulanan besin çözeltilerinin pH'sının 5.6-6.8'e (Günay 1981) ayarlanmas1 gerekir.

İncelenen sera topraklarının elektriksel iletkenlik değerleri 0.128-3.700 $\mathrm{dS} \mathrm{m}^{-1}$ arasında değişmektedir (Çizelge 1). İncelenen sera toprak örneklerinin elektriksel iletkenlik (EC) değerleri Soil Survey Staff (1951)'a göre sinıflandırıldı̆̆ında $\% 28$ 'inin tuzsuz, $\% 22$ 'sinin hafif tuzlu, \%19'unun orta tuzlu, \%19'unun tuzlu, \%9'unun yüksek tuzlu ve \%9'unun çok yüksek tuzlu sınıfinda yer aldığı belirlenmiştir (Çizelge 2).

Çizelge 1. Toprak örneklerinin fiziksel ve kimyasal analiz sonuçlarının minimum ve maksimum değerleri.

Table 1. Minimum and maximum values of chemical and physical analysis results of soil samples.

\begin{tabular}{lcc}
\hline Parametreler & Minimum & Maksimum \\
\hline $\mathrm{pH}$ & 6.9 & 8.7 \\
$\mathrm{CaCO}_{3}(\%)$ & 0.8 & 54.5 \\
$\mathrm{EC}\left(\mathrm{dS} \mathrm{m}^{-1}\right)$ & 0.128 & 3.700 \\
$\mathrm{OM}(\%)$ & 0.9 & 6.2 \\
$\mathrm{~N}(\%)$ & 0.04 & 0.31 \\
$\mathrm{P}\left(\mathrm{mg} \mathrm{kg}^{-1}\right)$ & 3 & 460 \\
$\mathrm{~K}\left(\mathrm{mg} \mathrm{kg}^{-1}\right)$ & 42 & 1350 \\
$\mathrm{Ca}\left(\mathrm{m} \mathrm{kg}^{-1}\right)$ & 1982 & 6177 \\
$\mathrm{Mg}\left(\mathrm{mg} \mathrm{kg}^{-1}\right)$ & 100 & 2325 \\
\hline
\end{tabular}

İncelenen sera toprak örneklerinin \%31'i kumlu killi tın, \%19'u tın, \%38'i kumlu tın, \%3'ü siltli tın, \%3'ü kil ve \%6's1 killi tın bünyeye sahiptir. Üreticilerin ağır toprak bünyesinin olumsuz etkilerinden kaçınmak amaciyla dere kumunu seralarına taşımasından dolayı geniş bir bünye dağılımının tespit edildiği düşünülmektedir. Sera toprak örneklerinin organik madde miktarları \%0.9-6.2 arasında değişmekte olup, örneklerin \%31'i humusça fakir, \%58'i az humuslu ve \%11'i humuslu sınıfında yer almıştır. Bölgemiz sera topraklarının büyük bir bölümünün organik madde miktarının düşük olduğu belirlenmiştir. Çiftlik gübresi, kompost ve üretim dönemi sonunda atılan bitki atıklarının kullanılması çözüm yollarını oluşturmaktadır. Örneklerin toplam azot içerikleri \%0.04-0.31 arasında değişmektedir. Loué (1968)'e göre sınıflandırılan örneklerin \%42'sinin toplam azot konsantrasyonu'nun yetersiz olduğu tespit edilmiştir. Orman ve Kaplan (2004), Kumluca ve Finike yörelerindeki domates yetiştirilen sera topraklarının $\% 55$ 'inin toplam azot içeriğinin düşük olduğunu bildirmişlerdir. Sera sebze yetiştiriciliğinde fertigasyon uygulamaları verim ve kalite standartlarının yükseltilebilmesi amacıyla düzenli olarak gerçekleştirilmektedir. Buna rağmen tespit edilen azot noksanlığının toprak organik madde miktarının yetersiz olmasından ve özellikle nitrat formundaki azotun yıkanabilme özelliğinden kaynaklandığı düşünülmektedir.

Toprak örneklerinin bitkiye yarayışlı fosfor içerikleri 3.0$460 \mathrm{mg} \mathrm{kg}{ }^{-1}$ arasında değişmekte olup, Olsen ve Sommers (1982)'ye göre siniflandırılan örneklerin \%97'sinin fosfor içeriğinin yeterli olduğu tespit edilmiştir. Öktüren Asri ve ark. (2008), Antalya bölgesinde patlican yetiștirilen sera topraklarının verimlilik düzeylerinin belirlenmesi amacıyla yaptıkları çalışmalarında sera topraklarının \%98'inin fosfor konsantrasyonunun yeterli olduğunu bildirmişlerdir.

$\mathrm{Bu}$ konuda yapılmış araştırma sonuçlarına göre sera topraklarının fosfor içeriklerinin yüksek olmasına rağmen Olsen ve Sommers (1982) tarafindan verilen sinır değerlerinin optimum bitki beslenme durumunun sağlanması ve ürün veriminin arttırılması açısından yeterli olmadığı, bildirilen sınır değerlerinin çalışmaların yürütüldüğü bölge koşullarında ürün miktarları dikkate alınarak yeniden belirlenmesi gerektiği bildirilmektedir.

Örneklerin değişebilir potasyum konsantrasyonları 42-1350 $\mathrm{mg} \mathrm{kg}$ arasında değişmekte olup; Pizer (1967)'a göre sınıflandırıldığında \%8'inin çok düşük, \%3'ünün düşük, \%11'inin yüksek ve \%78'inin çok yüksek düzeyde olduğu tespit edilmiştir. Öktüren Asri ve ark. (2008), Antalya bölgesinde patlıcan yetiştirilen sera topraklarının \%86'sının potasyum konsantrasyonunun yeterli olduğunu bildirmişlerdir. Toprak örneklerinin değişebilir kalsiyum konsantrasyonları 1982-6177 mg kg-1 arasında değişmekte olup; Loué (1968)'e göre sınıflandırılan örneklerin \%94'ü yüksek ve çok yüksek sınıfında yer almıştır. İncelenen sera toprak örneklerinin $\mathrm{pH}$ ve kireç kapsamları yüksek olduğu için, kalsiyum içerikleri de önemli ölçüde artmaktadır. Sönmez ve Kaplan (2007), Demre yöresinde domates yetiştirilen sera topraklarının \%76'sının kalsiyum konsantrasyonunun iyi sinıfinda yer aldığını bildirmişlerdir. Değişebilir magnezyum bakımından \%94'ü yüksek ve çok yüksek sınıfında yer alan örneklerin magnezyum konsantrasyonları 100-2325 $\mathrm{mg} \mathrm{kg}^{-1}$ arasında değişmektedir (Loué 1968). Sönmez ve ark. (1999), Kumluca ve Kale yörelerinde biber yetiştiriciliği yapılan sera topraklarının verimlilik durumlarının belirlenmesi amacıyla yaptıkları çalışmada, magnezyum içeriğinin iyi düzeyde olduğunu bildirmişlerdir. Bu sonuçlara göre Antalya ili Aksu ilçesinde patlıcan yetiştirilen sera topraklarının kalsiyum ve magnezyum içeriği bakımından büyük ölçüde yeterli olduğu ve beslenme açısından yetersizlikle ilgili bir sorun görülmediği açıktır. Ancak, bu elementlerin diğer bitki besin elementleri ile antagonistik etkileşimler oluşturarak alımlarını kısıtlayacakları da göz ardı edilmemelidir. 
Çizelge 2. Toprak örneklerinin sınır değerlerine göre sınıflandırılması.

Table 2. Evaluation of soil samples according to the limit values.

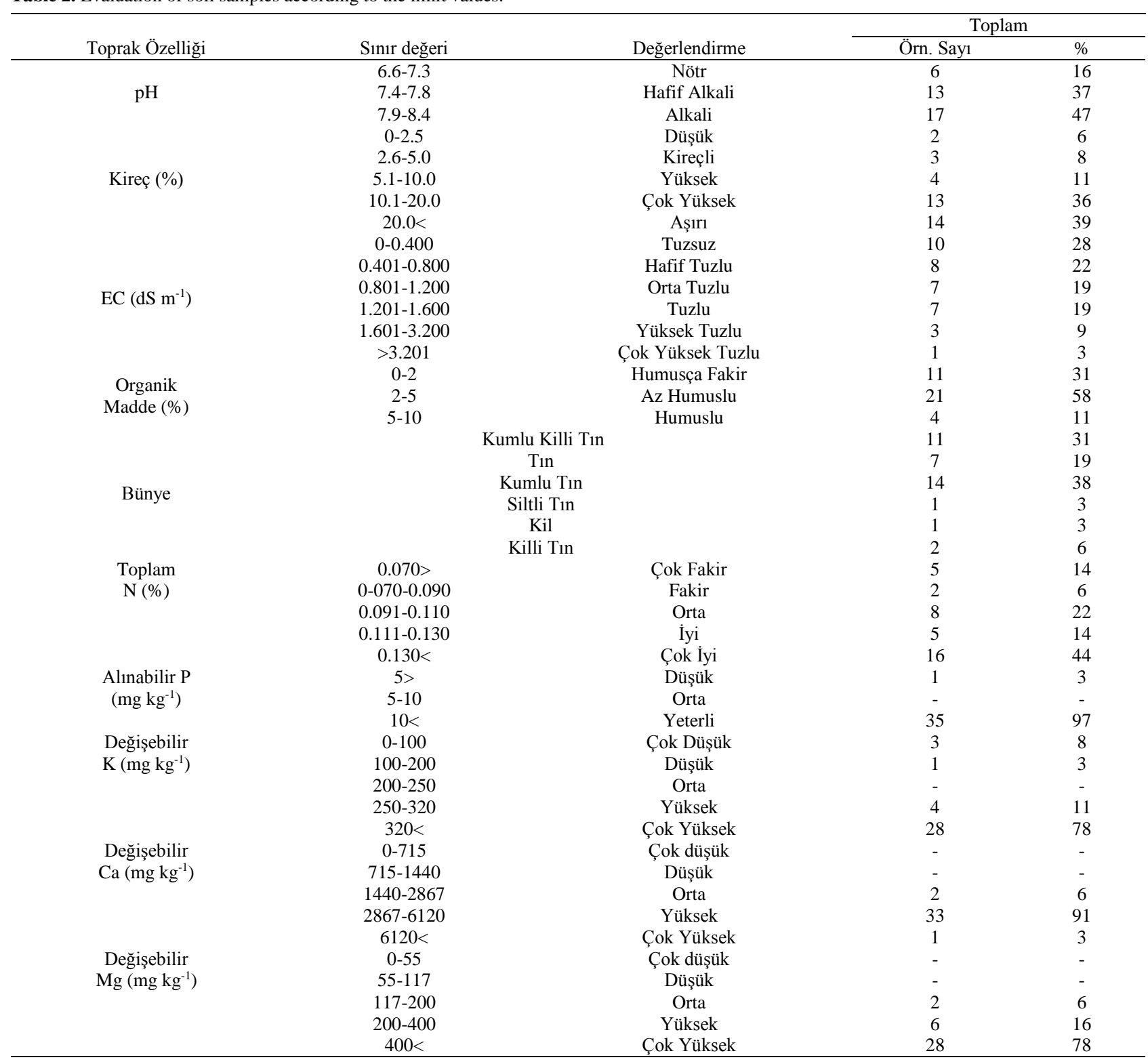

\section{Sonuç}

İncelenen sera topraklarının büyük çoğunluğu hafif alkalin ve alkalin karakterde olup kireç içerikleri yüksektir. Patlıcan bitkisinin hafif asit ve nötr koşulları tercih ettiği göz önüne alındığında; mineral gübrelerin fizyolojik asit karakterli olanları tercih edilirken, sulama suyuna asit eklenerek besin çözeltilerinin pH'sı ayarlanmalıdır. İncelenen sera topraklarının organik madde miktarı düşüktür. Sera topraklarında organik madde düzeyini artırmak, mikrobiyal aktiviteyi teşvik etmek ve toprağın bazı fiziksel özelliklerini düzeltebilmek için; dikim öncesi organik materyal uygulamalarına önem verilmelidir. Bu bağlamda yetiştirme sezonu sonunda oluşan hasat sonrası atıklardan kompost olarak yararlanılması hem toprak organik madde miktarını arttıracak hemde bitki organlarıyla atılan bitki besin elementlerinin geri dönüşümünü sağlayacak önemli bir kaynaktır. Bölgede yapılan diğer çalışmalarda olduğu gibi, bu çalışmada da sera topraklarında yüksek bir fosfor birikimi tespit edilmiştir. Ancak sera sebze yetiştiriciliğinde Olsen ve Sommers (1982) tarafından verilen sınır değerlerinin optimum bitki beslenme durumunun sağlanması ve ürün veriminin arttırılması açısından yeterli olmadığ $\breve{1}$, bildirilen sınır değerlerinin çalışmaların yürütüldüğü bölge koşullarında ürün miktarları dikkate alınarak yeniden belirlenmesi gerektiği düşünülmektedir.

İncelenen toprak örneklerinin Antalya bölgesi patlıcan sera topraklarının kalsiyum ve magnezyum içeriği bakımından büyük ölçüde yeterlidir. Fazla kireç, yüksek kil içeriği, yetersiz nem ve profil gelişimi gibi ülkemiz topraklarının genel karakteristik özellikleri sonucunda bu bitki besin elementlerinin topraktaki içerikleri yüksek olmaktadır. Bu elementlerin diğer bitki besin elementleri ile antagonistik etkileşimler oluşturarak alımlarını kısıtlayacakları da göz ardı edilmemelidir. 


\section{Kaynaklar}

Black CA (1965) Methods of soil analysis, part 2, chemical and microbiological properties, American Society of Agronomy Inc., Publisher Madison, Wilconsin, USA. 1372-1376.

Bouyoucos GJ (1955) A recalibration of the hydrometer method for making mechanical analysis of the soils. Agronomy Journal 4(9): 434.

Evliya H (1964) Kültür bitkilerinin beslenmesi. Ankara Üniversitesi Ziraat Fakültesi Yayınları Sayı: 10.

Günay A (1981) Özel sebze yetiştiriciliği (Serler). Cilt II, Çağ Matbaas1, Ankara.

Işıkhan HT, Sönmez S (2017) Yayla Koşullarında Domates Yetiștiriciliği Yapılan Sera Topraklarının Verimlilik Durumlarının Belirlenmesi: Elmalı Yöresi Örneği. Derim Dergisi 34(1): 79-84.

Jackson ML (1967) Soil Chemical Analysis. Prentice Hall of India Private Limited, New Delhi.

Kacar B (1995) Toprak analizleri. Bitki ve toprağın kimyasal analizleri: III. Ankara Üniversitesi Ziraat Fakültesi Eğitim Araştırma ve Geliştirme Vakfı Yayınları, No: 3, Ankara.

Loué A (1968) Diagnostic Petiolaire de Prospection. Etudes Sur la Nutrition et la Fertilisation Potassiques de la Vigbe Societe Commerciale des Potasses d'Alsace Services Agroomiques 31-41.

Olsen SR, Sommers EL (1982) Phosporus Soluble in Sodium Bicarbonate, Methods of Soil Analysis, Part 2, Chemical and Microbiological Properties. Edit: A.L. Page, P.H. Miller, D.R. Keeney, pp. 404-430.

Orman Ş, Kaplan M (2004) Kumluca ve Finike Yörelerinde Serada Yetiştirilen Domates Bitkisinin Beslenme Durumunun Belirlenmesi. Akdeniz Üniversitesi Ziraat Fakültesi Dergisi 17(1): 19-29.

Öktüren Asri F, Arı N, Arpacıoğlu EA, Demirtaş EI, Aslan DH (2008) Antalya Bölgesinde Patlıcan Yetiştirilen Sera Topraklarının Bazı Verimlilik Özelliklerinin Belirlenmesi. VII. Sebze Tarımı Sempozyumu, Yalova, s. 379-382.

Pizer NH (1967) Some Advisory Aspect. Soil Potassium and Magnesium, Technical Bullettin No. 14: 184.

Soil Survey Staff (1951) Soil Survey Manual. Agricultural Research Administration, U.S. Dept. Agriculture Handbook No: 18.

Sönmez İ, Kaplan M (2007) Antalya-Demre Yöresinde Domates Yetiştirilen Sera Topraklarının Bazı Verimlilik Özelliklerinin Değerlendirilmesi. Akdeniz Üniversitesi Ziraat Fakültesi Dergisi 20(1): 29-35.

Sönmez S, Uz İ, Kaplan M, Aksoy T (1999) Kumluca ve Kale Yörelerindeki Seralarda Yetiştirilen Biberlerin Beslenme Durumlarının Belirlenmesi. Turkish Journal of Agriculture and Forestry 23(2): 365-373.

TUİK (2015) http://www.tuik.gov.tr. Erişim 17 Kasım 2018. 